\title{
Specific exposure of ICU staff to SARS-CoV-2 seropositivity: a wide seroprevalence study in a French city-center hospital
}

\author{
Emmanuel Vivier ${ }^{1,3^{*}} \mathbb{D}$, Caroline Pariset $^{2}$, Stephane Rio ${ }^{3}$, Sophie Armand ${ }^{3}$, Fanny Doroszewski ${ }^{3}$, \\ Delphine Richard ${ }^{3}$, Marc Chardon ${ }^{4}$, Georges Romero ${ }^{5}$, Pierre Metral ${ }^{6}$, Matthieu Pecquet ${ }^{7}$ and Adrien Didelot ${ }^{3,8}$
}

\begin{abstract}
Background: Most hospital organizations have had to face the burden of managing the ongoing COVID-19 outbreak. One of the challenges in overcoming the influx of COVID-19 patients is controlling patient-to-staff transmission. Measuring the specific extent of ICU caregiver exposure to the virus and identifying the associated risk factors are, therefore, critical issues. We prospectively studied SARS-CoV-2 seroprevalence in the staff of a hospital in Lyon, France, several weeks after a first epidemic wave. Risk factors for the presence of SARS-CoV-2 antibodies were identified using a questionnaire survey.
\end{abstract}

Results: The overall seroprevalence was 9\% (87/971 subjects). Greater exposure was associated with higher seroprevalence, with a rate of 3.2\% [95\% Cl 1.1-5.2\%] among non-healthcare staff, 11.3\% [8.9-13.7\%] among all healthcare staff, and 16.3\% [12.3-20.2\%] among healthcare staff in COVID-19 units. The seroprevalence was dramatically lower (3.7\% [1.0-6.7\%]) in the COVID-19 ICU. Risk factors for seropositivity were contact with a COVID-19-confirmed household (odds ratio (OR), 3.7 [1.8-7.4]), working in a COVID-19 unit (OR, 3.5 [2.2-5.7], and contact with a confirmed COVID-19 coworker (OR, 1.9 [1.2-3.1]). Conversely, working in the COVID-19-ICU was negatively associated with seropositivity (OR, $0.33[0.15-0.73])$.

Conclusions: In this hospital, SARS-CoV-2 seroprevalence was higher among staff than in the general population. Seropositivity rates were particularly high for staff in contact with COVID-19 patients, especially those in the emergency department and in the COVID-19 unit, but were much lower in ICU staff.

Clinical trial registration NCT04422977

Keywords: COVID-19, SARS-CoV-2 seroepidemiologic studies, Health personnel

\section{Background}

Since its outbreak in January 2019 in Wuhan, China, the coronavirus disease 2019 (COVID-19) pandemic has burdened healthcare systems worldwide [1-3]. As suspected and recently identified, one of the main difficulties in managing the outbreak has been the specific exposure

\footnotetext{
*Correspondence: evivier@ch-stjoseph-stluc-lyon.fr

${ }^{1}$ Medecine Intensive Reanimation, Centre Hospitalier Saint Joseph Saint Luc, 20 Quai Claude Bernard, 69007 Lyon, France

Full list of author information is available at the end of the article
}

of hospital staff [4-7]. Evidence and an understanding of the risk factors for staff infection remain lacking, however. Hospitals concentrate many infected patients and may be significant spreaders of the disease. Intra-hospital clusters among staff may emerge and induce secondary nosocomial infections. The effectiveness of personal protective measures and equipment for caregivers has been well demonstrated, but its use remains imperfect for several reasons: insufficient training, errors of use, and caregivers fatigue $[8,9]$. The spread of COVID-19 has been facilitated by the frequency of mildly symptomatic and 
asymptomatic forms, and by the length of the incubation period of the virus [10]. Contact tracing and screening and the tracking of intra-hospital epidemic outbreaks are, therefore, very difficult $[11,12]$. The unusual and rapid influx of patients has required hospitals to reorganize, with the accelerated training of healthcare teams further increasing the risk of an imperfect implementation of protective measures.

We report a large prospective study of severe acute respiratory syndrome coronavirus 2 (SARS-COV-2) seroprevalence among the staff of a city-center hospital in Lyon, France, where there was an influx of COVID-19 patients in March-April 2020. The aims of the study were to determine the overall SARS-COV-2 seroprevalence rate in the hospital staff, and to identify and quantify risk factors for symptomatic and asymptomatic staff infection. The main research questions were (i) whether seroprevalence was higher in healthcare personnel than in non-healthcare staff, (ii) whether working in units managing COVID-19 patients increased the risk of infection and (iii) whether a specific exposure was associated with working in intensive care unit.

\section{Methods}

\section{Hospital description and epidemic background}

Saint Joseph Saint Luc Hospital is a tertiary city-center hospital located in Lyon, in the Auvergne-Rhône-Alpes region in France, where the first wave of the COVID19 pandemic occurred in March and April 2020. The hospital was strongly involved in tackling the epidemic, mainly through its emergency department and intensive care unit (Fig. 1). The first case was detected on February 26th, and 250 patients with confirmed COVID-19 were eventually hospitalized until June, including $11 \%$ in the intensive care unit. The rapid influx of a large number of COVID 19 patients relative to the hospital's capacity (320 beds) meant that an equally rapid reorganization of the hospital's treatment units was required. Elective surgery was stopped and specific COVID units were opened to screen patients with suspected COVID-19 (and await $\mathrm{CT}$ and/or RT-PCR results) and treat patients with confirmed COVID-19. The capacity of the intensive care unit was increased by $40 \%$. Work meetings were limited and when possible, staff were placed on leave or worked remotely. Family visits were banned. The staff restaurant remained open, but strict social distancing measures were enforced. Each confirmed case among staff was investigated to limit further intra-hospital infections by contact tracing and screening of symptomatic suspects.

\section{Study design}

After the first European wave of the epidemic had passed, SARS-CoV-2 antibody testing and a dedicated survey questionnaire were offered to all persons who had worked at the Saint Joseph Saint Luc hospital in Lyon, Auvergne-Rhône-Alpes, France, from March 1 to April 30 2020. This included all clinical and nonclinical employees, the staff of the subcontracted cleaning company, medical interns and nursing students. Testing was delayed by 6 weeks after the end of the first wave to maximize the sensitivity of the antibody test. Enrollment was free, anonymous and voluntary. The study was registered at ClinicalTrials.gov (NCT04422977) and was approved by the local ethics committee (Comité de Protection des Personnes SUD-EST II, Bron, France). Written informed consent was obtained from all participants. The inclusion period ran from June 8 to June 30, 2020, 1 month after the end of the lockdown in France.

\section{Survey}

Participants were asked to complete a dedicated questionnaire (see Questionnaire in Additional file 1). The following parameters were recorded: age, gender, presence of symptoms during the outbreak, and prior COVID-19 RT-PCR results. To determine risk factors for COVID19 infection, participants were asked to state their occupation, the main locations of their work in the hospital, whether they were in direct contact with patients (healthcare workers) or not (non-healthcare workers) and whether they worked day or night shifts. They were also asked to indicate whether they had been in contact with a RT-PCR confirmed COVID-19 household, colleague or patient. Finally, participants were asked about their use of personal protective equipment, social distancing, where they worked in the hospital, and any mandated work time reduction or telework.

\section{Serological analysis}

The samples were collected in lithium heparin gel separator tubes, centrifuged and kept at $-20{ }^{\circ} \mathrm{C}$ until analysis. All tests were carried out after calibrating the analyzer. Before performing the test, the samples were thawed and re-centrifuged. The SARS-Cov-2 serology tests were performed using electrochemiluminescence immunoassays (Elecsys Anti-SARS-CoV-2, C6000, E601 analyzer Roche Diagnostics). In these tests, a recombinant nucleoprotein is used to detect total anti-SARS-CoV2-2 immunoglobulins against nucleopcapsid antigen (IgA, IgM and IgG), a technique whose sensitivity and specificity 14 days after a positive SARS-Cov-2 RT-PCR test have been reported as $>99 \%$ [13-15]. Participants were considered seropositive for SARS-CoV-2 if their test results were above the manufacture-specified threshold. 


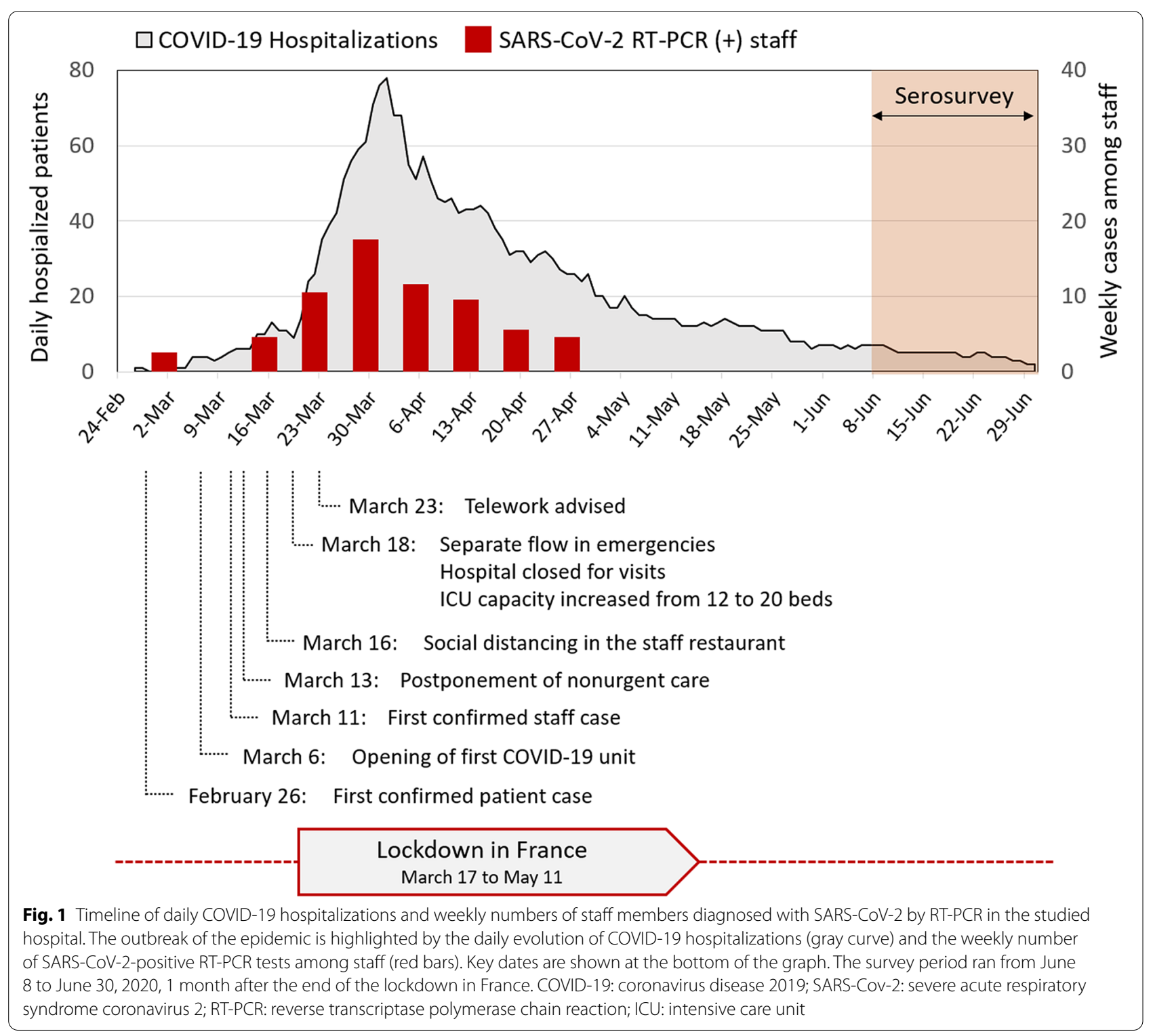

\section{Statistical analysis}

As the population seroprevalence of SARS-CoV-2 in Auvergne-Rhône-Alpes was unknown at the time of designing the study, the necessary sample size was calculated considering hypothetical seropositivity rates of $15 \%$ in unexposed patients and $30 \%$ in exposed patients. The estimated sample size required to detect a statistically significant difference between exposure and non-exposure at an $\alpha$ level of 0.05 and a power $(1-\beta)$ of 0.9 was 100 participants per group. The expected participation rate was $70 \%$ of staff, i.e., 900 persons.

Overall and group-specific seroprevalences were calculated as the ratios of subjects tested with positive serology tests divided by the total number of subjects in each group, expressed as absolute and relative frequencies. Ninety-five percent confidence intervals were estimated using the asymptotic approximation. Age was expressed as median [IQP]. In univariate analysis, proportions were compared using $X^{2}$ tests or Fisher exact tests (depending on sample size) and ages were compared using Mann-Whitney $U$ tests. Reported symptoms and exposure factors associated with positive serology tests were then successively assessed by means of multivariate logistic regression analyses. The maximal model included all exposures associated at $P<0.15$ with a positive serology test. The final model included all variables significantly associated $(P<0.05$, two tailed) with a positive serology test. All statistical 
analyses were performed with SPSS version 20 (IBM, Chicago, IL).

\section{Results}

Among the 1299 staff who worked in the hospital during the first wave of the COVID-19 epidemic, 971 (75\%) completed the questionnaire survey and were tested for anti-SARS-CoV-2 Ig antibodies. (Additional file 2: Figure S1). These respondents were representative of all occupations and areas in the hospital (Additional file 3: Table S1 and S2). They included 155 physicians, 274 nurses, 111 nursing assistants, 282 support and administrative staff, and 149 others. Eighty-seven subjects had positive SARS$\mathrm{CoV}-2$ antibody tests, such that the overall seroprevalence in the study group was 9\% [8.8-9.2\%]. There was no significant association between SARS-CoV-2 seropositivity and sex, (male sex, 20/87 [23.0\%] vs 213/884 [24.1\%], $P=0.87$ ) but seropositive staff were slightly younger on average (median age, 37 [28-47] vs 39 [31-51] years, $P=0.02)$.

\section{Symptoms}

Forty-two percent of subjects (410/971) reported at least one prior symptom but this was not a highly sensitive ([76/87] 87\%) or specific ([550/884] 62\%) sign. Of the 87 members of staff with positive SARS-CoV-2 antibody tests, 11 (12.6\%) reported no prior symptoms. Overall, the positive predictive value of declaring one or more prior symptoms was very low $(76 / 410[18 \%])$. However, anosmia $(\mathrm{OR}=55.3)$ and fever $(\mathrm{OR}=3.5)$ were strongly associated with subsequent seropositivity (Additional file 4: Table S3). Fifty of the 87 subjects with positive SARS-CoV-2 antibody tests had previously had a RTPCR test for SARS-CoV-2, which was positive in 41/50 cases (84\%). One subject who had had a positive RT-PCR test had a negative antibody test.

\section{Exposure factors associated with SARS-CoV-2 seropositivity}

Being involved in clinical care was significantly associated with SARS-CoV-2 seropositivity (78/689 positive antibody tests [11.3\%] among healthcare personnel vs. 9/282 [3.2\%] in non-healthcare personnel; $P<0.001$ ) (Table 1). In univariate analysis, the seropositivity rate was particularly high among nurses (38/274 [13.9\%], $P=0.001)$ and was also significantly higher in staff who reported working in COVID-19 units than in those who reported working in non-COVID-19 units (68/577 [11.8\%] vs $10 / 174$ [5.7\%], $P=0.02$ ) (Table 2). The prevalence of seropositivity was especially high in emergency department staff, the COVID-19 screening unit and the COVID-19 treatment unit, but much lower in those working in the COVID-19-ICU, with respective rates of 26/159 (16.4\%), 35/211 (16.6\%), 28/185 (15.1\%) and 7/191 (3.7\%) (Fig. 2).

Reporting a personal contact with a confirmed COVID-19 household, a confirmed COVID-19 coworker

Table 1 Proportion of SARS-COV-2 seropositive staff by occupation,

\begin{tabular}{|c|c|c|c|c|}
\hline Function & $\begin{array}{l}\text { Workers per } \\
\text { occupation }\end{array}$ & $\begin{array}{l}\text { SARS-CoV-2 seropositive staff in } \\
\text { the category (\%) }\end{array}$ & $\begin{array}{l}\text { SARS-CoV-2 seropositive staff out of } \\
\text { the category (\%) }\end{array}$ & $P^{*}$ \\
\hline All staff & 971 & 9 & - & - \\
\hline Healthcare staff & 689 & 11.3 & 3.2 & $<0.001$ \\
\hline Physicians & 155 & 12 & 8.2 & 0.06 \\
\hline Nurses & 274 & 13.9 & 7 & 0.001 \\
\hline Nursing assistants & 111 & 12.6 & 8.5 & 0.15 \\
\hline Midwives & 27 & 3.7 & 9.1 & 0.33 \\
\hline Radiology technicians & 23 & 4.3 & 9.1 & 0.71 \\
\hline Cleaning staff & 39 & 7.7 & 9 & $>0.99$ \\
\hline Porters & 11 & 9.1 & 9 & $>0.99$ \\
\hline Others & 49 & 0 & 9.4 & 0.02 \\
\hline Non-healthcare staff & 282 & 3.2 & 11.3 & $<0.001$ \\
\hline Management staff & 52 & 0 & 9.5 & 0.01 \\
\hline Nurse managers & 37 & 0 & 9.3 & 0.07 \\
\hline Medical secretaries & 70 & 5.7 & 9.2 & 0.39 \\
\hline $\begin{array}{l}\text { Laboratory and sterilization } \\
\text { technicians }\end{array}$ & 43 & 4.7 & 9.2 & 0.42 \\
\hline Caterers & 10 & 10 & 8.9 & 0.61 \\
\hline Others & 70 & 2.9 & 9.4 & 0.79 \\
\hline
\end{tabular}

SARS-CoV-2: severe acute respiratory syndrome coronavirus

*Proportions of seropositive staff in each category are compared to the proportions of seropositive staff in the other categories with $\mathrm{x}^{2}$ test or Fischer exact test 
Table 2 Exposure factors associated with SARS-CoV-2 seropositivity in hospital staff. Univariate analysis

\begin{tabular}{|c|c|c|c|}
\hline \multirow[t]{2}{*}{ Exposure factor } & \multicolumn{2}{|c|}{ Proportion of SARS-CoV-2 seropositive staff (\%) } & \multirow[t]{2}{*}{$P$} \\
\hline & Exposure present & Exposure absent & \\
\hline \multicolumn{4}{|l|}{ Contacts } \\
\hline COVID-19+ coworker & 33/195 (16.9) & $54 / 776(7.0)$ & 0.001 \\
\hline COVID-19+household & $14 / 54(25.9)$ & 73/917 (8.0) & $<0.001$ \\
\hline COVID-19+ patient & 29/162 (17.9) & $58 / 809(7.2)$ & $<0.001$ \\
\hline \multicolumn{4}{|l|}{ Work areas } \\
\hline Any care unit & $78 / 752(10.4)$ & $9 / 219(4.1)$ & 0.004 \\
\hline Emergency department & 26/159 (16.4) & $61 / 812(7.5)$ & 0.001 \\
\hline COVID-19-free medical unit & $12 / 160(7.5)$ & $75 / 811(9.2)$ & 0.48 \\
\hline COVID-19-free surgical unit & $11 / 119(9.2)$ & $76 / 852(8.9)$ & 0.91 \\
\hline Operating room & $3 / 114(2.6)$ & $84 / 857(9.8)$ & 0.01 \\
\hline COVID-19 screening unit & $35 / 211(16.6)$ & $52 / 760(6.8)$ & $<0.001$ \\
\hline COVID-19 standard care unit & 28/185 (15.1) & $59 / 786(7.5)$ & 0.001 \\
\hline COVID-19 intensive care unit & 7/191 (3.7) & $80 / 780(10.3)$ & 0.004 \\
\hline \multicolumn{4}{|l|}{ Transmission prevention measures } \\
\hline Optimal use of personal protective equipment & $52 / 575(9)$ & 35/396 (8.8) & 0.91 \\
\hline Meals in the staff restaurant & $22 / 340(6.5)$ & $65 / 631(10.4)$ & 0.05 \\
\hline Meals in a break room of a COVID-19 unit & $45 / 259(17.4)$ & $42 / 712(5.9)$ & $<0.001$ \\
\hline Working time reduction $\geq 50 \%$ & $5 / 103(4.9)$ & $82 / 868(9.4)$ & 0.12 \\
\hline Telework & $7 / 194(3.6)$ & $80 / 777(10.3)$ & 0.004 \\
\hline
\end{tabular}

COVID-19: coronavirus disease 2019; SARS-Cov-2: severe acute respiratory syndrome coronavirus

or a confirmed COVID-19 patient were all significantly associated with higher seropositivity rates (33/195 [16.9\%], 14/54 [25.9\%] and 29/162 [17.9\%], respectively). On the other hand, working in the operating room, eating meals break in the staff restaurant, and telework during the lockdown were associated with lower incidences of positive antibody tests (3/114 [2.6\%], 22/340 [6.5\%] and 7/194 [3.6\%], respectively). Night work and the ability to maintain social distancing at work were not significantly associated with the seropositivity rate (data not shown). Table 2 lists all the univariate associations between exposure factors and antibody positivity. In multivariate logistic regression analysis, the three exposure factors positively associated with a higher seropositivity rate were contact with a confirmed COVID-19 household, contact with a confirmed COVID-19 coworker and working in a non-intensive care COVID-19 unit, with estimated odds ratios of 3.7 [95\% CI 1.8-7.4], 1.9 [95\% CI
$1.2-3.1]$ and 3.5 [95\% CI 2.2-5.7], respectively (Table 3). On the other hand, working in the COVID-19 ICU was associated with a lower rate of positive antibody tests $(\mathrm{OR}=0.33$, [95\% CI 0.15-0.73]).

\section{Discussion}

This cross-sectional seroprevalence study confirms that hospital workers may have a higher risk of SARS-CoV-2 infection. The risk seems to be particularly high for staff in direct contact with COVID-19 patients, the groups with the highest seropositivity rates in this study being emergency department and COVID-19 unit workers. In contrast, ICU staff had relatively lower seropositivity rates.

\section{Global seroprevalence}

The overall SARS-CoV-2 seroprevalence rate among hospital staff (9\%) was twice the estimated community

\section{(See figure on next page.)}

Fig. 2 Risks of exposure to SARS-CoV-2 infection in different areas of the hospital. a Schematic illustration of the hospital's single-block architecture with administrative and support areas in gray, non-COVID treatment units in pink and COVID-19 treatment units in red. Surgical units include: plastic and reconstructive surgery, urology, vascular surgery, orthopedics, gynecology and digestive surgery (5th Floor). Non-COVID-19 treatment units include: nephrology, endocrinology, rheumatology, gastroenterology, neurology, infectious disease, internal medicine, cardiology (3rd Floor) and cardiologic intensive care unit (5th Floor). b, c Staff SARS-CoV-2 seroprevalence (b) in the different work areas (non-treatment areas, non-COVID-19 treatment areas, COVID-19 treatment areas) and $\mathbf{c}$ in the different COVID-19 units. COVID-19: coronavirus disease 2019; SARS-Cov-2: severe acute respiratory syndrome coronavirus 2; ICU: intensive care unit 


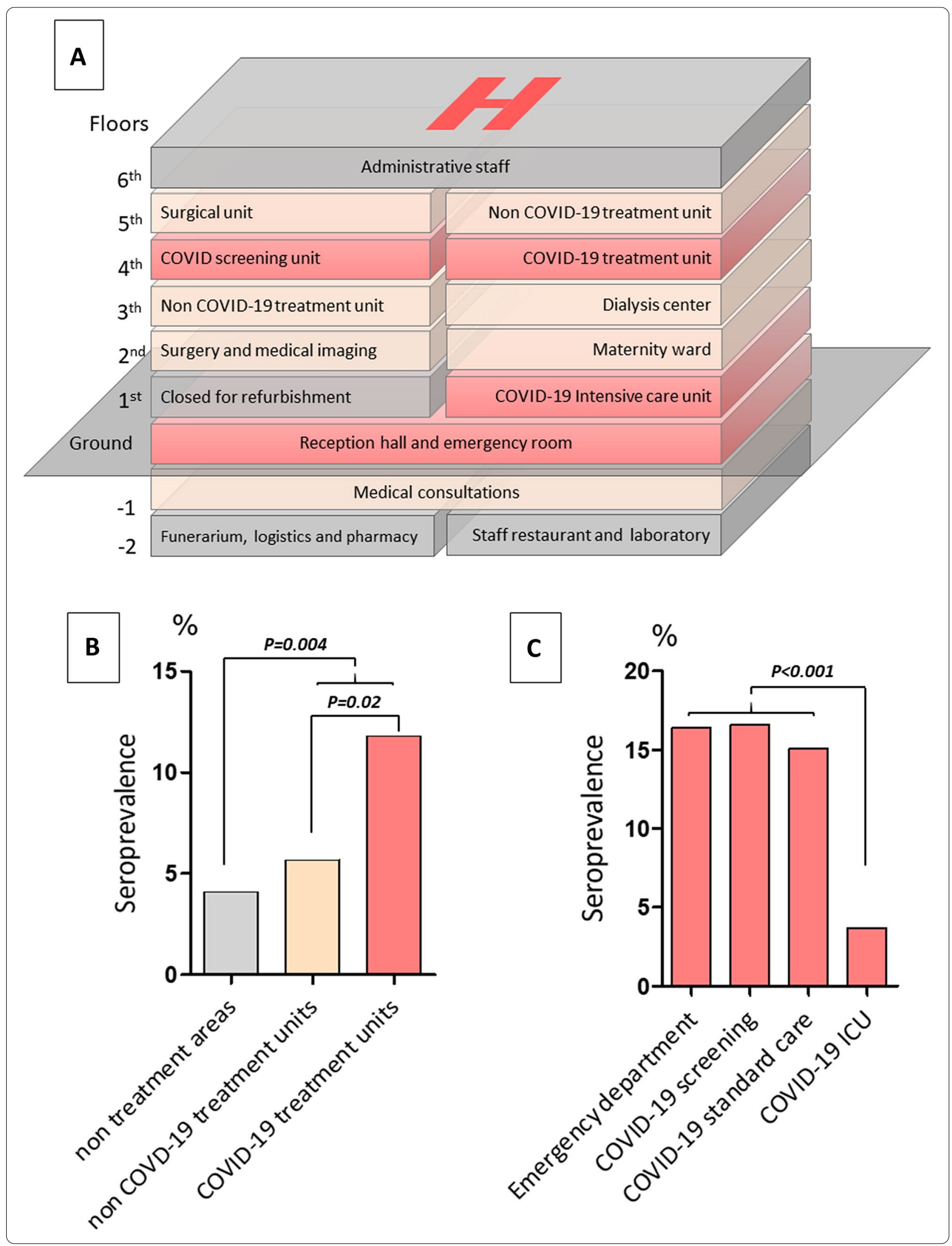


Table 3 Exposure factors associated with SARS-CoV-2 seropositivity in hospital staff

\begin{tabular}{lcc}
\hline Exposure factors & Odds ratio $(\mathbf{9 5 \%} \mathrm{Cl})$ & $\boldsymbol{P}$ \\
\hline Contact with COVID-19+ coworker & $1.9(1.16-3.12)$ & 0.01 \\
Contact with COVID-19+ household & $3.67(1.83-7.38)$ & $<0.001$ \\
Worked in standard care COVID-19 unit & $3.54(2.2-5.7)$ & $<0.001$ \\
Worked in COVID-19 ICU & $0.33(0.15-0.73)$ & 0.007 \\
\hline
\end{tabular}

Results of multivariate analysis by stepwise backward logistic regression COVID-19: coronavirus infectious disease 2019; ICU: intensive care unit

seroprevalence in the hospital catchment area during the screening period (3-5\%) [16, 17]. The prevalence of infections among hospital staff across Europe was characterized by a great diversity during the first phase, ranging from 2 to $30 \%$ according to countries and area [5, $18-20]$. This high variability is related not only to local prevalence of community infection but also to specific hospital measures to contain the infection.

This result is significant, because only $41 / 87$ subjects had previously been diagnosed by RT-PCR. While RTPCR remains essential for contact tracing, this technique is limited by its low sensitivity and the fact that the virus may no longer be present at the time of screening [21]. The positive predictive value of a symptom declaration for positive serology was very weak in our study, this uncommon result could be explained by technical (weak sensibility of the electrochemiluminescence test) or methodological biases (suggestive questionnaire, nonspecific symptoms, long study period, sero-reversion before the survey). Furthermore, the rate of asymptomatic seropositive workers was only $13 \%$, which contrasts with other series $(20-30 \%)[20,22]$. This low rate could also be explained by overdeclaration of symptoms, low sensitivity of the test, possible sero-reversion and a global low seroprevalence in our cohort.

\section{Exposure risk factors}

In keeping with the results of a recent hospital-wide survey in Belgium, we found that the primary risk factor for SARS-CoV-2 seropositivity was contact with a confirmed COVID-19 household [19]. However, this factor must be interpreted with caution, as the delay between contact and the seroprevalence study makes it impossible to determine whether the contact with confirmed COVID-19 was indeed the initial source of the infection or was secondarily infected by the member of staff. Our study also highlights the risk of intra-hospital spread, contact with a COVID-19-positive coworker being associated with a twofold increase in the risk of SARSCoV-2 seropositivity. Working in units where COVID-19 patients were treated was a strong risk factor for subsequent SARS-CoV-2 seropositivity. This may be due in part to the shortage of personal protective equipment at the start of the epidemic, as reported in other series [20, 23]. Another special difficulty was to apply social distancing measures in a hospital environment, especially during the staff meals. Indeed, eating in a break room of a COVID care unit was strongly associated with a higher seroprevalence, in univariate analysis. Saint Joseph Saint Luc is a small single-block city-center hospital with small and tightly packed treatment areas. By contrast, having lunch in the staff restaurant seems to have been a protective factor. The restaurant is more spacious and ventilated and the social distancing seems to have been better defined and respected there.

A similar seroprevalence study conducted in a Spanish hospital facing a higher local epidemic wave within the same period reveals some concordant conclusions: higher infection rate among caregivers vs. non-caregivers [20]. But differently from us, the authors showed the lack of PPE and a previous contact with COVID-19 patients were independent factors that were associated with SARS-CoV-2 infection. The seroprevalence was the highest among porters.

We found that staff treating COVID-19 patients in the ICU had a much lower than average SARS-CoV-2 seropositivity rate. This result is in line with a similar previous study [22]. It is of particular clinical significance as it concerns both regular ICU staff and (about 90) additional crisis support personnel. This relatively low seroprevalence may stem from the particular focus on intensive care at the start of the epidemic, with less shortage in protective personal equipment and high standards of infection control. The closed circuit ventilation of intubated patients may also have limited the spread of the virus and the risk of aerosolization with non-invasive techniques seems to be limited [24, 25]. The staff/ patient ratio is higher in intensive care than in standard care units with lower patient turnover, which may have reduced individual risks of exposure [26]. Furthermore, patients are often admitted to intensive care 5-8 days after first presenting symptoms and may, therefore, have a lower viral load during their ICU stay [27].

Interestingly, ICU workers had no less household contact but significantly less COVID-19 coworker contact than others hospital workers $(5.1 \%$ vs. $5.7 \%, P=0.76$ and $20.9 \%$ vs $30.1 \%, P=0.01$ ). These data highlight the responsibility of staff clusters in the intra-hospital spread of SARS-Cov-2.

\section{Strengths and limitations}

The strengths of the study are the large number of staff included throughout the hospital (including both healthcare and non-healthcare workers), the short data collection time and the optimal delay between the 
peak of the epidemic and the survey. Recent data show that seroconversion can be delayed by up to 3 weeks after infection with SARS-CoV-2, especially in cases of mildly symptomatic disease [28]. This could explain the discrepancies between the results of our study and those of Steensels et al. [19].

The limitations of the study are first, its single center design, which means that any generalization of the results should be made with caution. Second, since some staff members chose not to participate in the study, selection bias cannot be excluded. Third, to respect patient confidentiality, the questionnaires were self-administered and anonymous, leading to possible errors or misunderstandings. Fourth, we used an automated electrochemiluminescence immunoassay to detect total anti-SARS-CoV-2 antibodies and not a differential detection of IgM and igG with ELISA (enzyme linked immunosorbent assay); however, recent data suggest a good agreement between the two methods [14]. Fifth, given the three-month delay between the first case of COVID-19 in a healthcare worker and the survey, some degree of sero-reversion may have contributed to underestimating global seroprevalence. Recent data suggest that antibody responses could decrease rapidly (especially in moderate forms) [29, 30].

\section{Conclusion}

In this study, hospital staff treating COVID-19 patients were at a high risk of intra-hospital infection. This suggests that prevention measures should be improved and infection clusters tracked carefully in COVID-19 units. Our results indicate that the risk of exposure seems to be unevenly distributed throughout hospitals, seropositivity rates being higher than average in the emergency department and (standard care) COVID-19 unit where patient turnover was high, and this is where prevention efforts should be focused in managing the epidemic. The relatively low seropositivity rate observed in COVID-19 intensive care staff suggests that intra-hospital patient-to-staff transmission is limited in this area.

\section{Supplementary Information}

The online version contains supplementary material available at https://doi. org/10.1186/s13613-021-00868-8.

Additional file 1. Questionnnaire for participants.

Additional file 2: Figure S1. Enrollment of study participants.

Additional file 3: Table S1. Stratification of the sample by work area. Table S2. Participation rates according to healthcare workers category.

Additional file 4: Table S3. Symptoms associated with SARS-CoV-2 seropositivity in hospital staff
Acknowledgements

The authors would like to thank all the staff of the Saint Joseph Saint Luke Hospital for their participation.

\section{Authors' contributions}

EV, PM, MP and AD designed the study. MP, SR, FD, SA, and DR organized and performed the data collection. EV performed the statistical analysis. EV, and AD made substantial contributions to the analysis and interpretation of the data. EV and AD wrote the manuscript. All authors had full access to the study data, contributed to drafting the manuscript or critically revised its content, approved the final version of the manuscript, and take responsibility for the integrity of the data and the accuracy of the data analysis. EV is the guarantor of the paper. All authors read and approved the final manuscript.

\section{Funding}

The study was supported by hospital funding.

Availability of data and materials

The datasets used and/or analyzed during the current study are available from the corresponding author on reasonable request.

\section{Declarations}

\section{Ethics approval and consent to participate}

The study was approved by the local ethics committee (Comité de Protection des Personnes SUD-EST II, Bron, France) and written informed consent was obtained from all participants.

\section{Consent for publication}

Not applicable.

\section{Competing interests}

The authors declare no competing interests.

\section{Author details}

${ }^{1}$ Medecine Intensive Reanimation, Centre Hospitalier Saint Joseph Saint Luc, 20 Quai Claude Bernard, 69007 Lyon, France. ${ }^{2}$ Maladies Infectieuses, Centre Hospitalier Saint Joseph Saint Luc, Lyon, France. ${ }^{3}$ Unite de Recherche Clinique, Centre Hospitalier Saint Joseph Saint Luc, Lyon, France. ${ }^{4}$ Medecine du travail, Centre Hospitalier Saint Joseph Saint Luc, Lyon, France. ${ }^{5}$ Gestion de La Qualite Et du Risque, Centre Hospitalier Saint Joseph Saint Luc, Lyon, France. ${ }^{6}$ Departement D'Information Medicale, Centre Hospitalier Saint Joseph Saint Luc, Lyon, France. ${ }^{7}$ Laboratoire de Biologie Medicale, Centre Hospitalier Saint Joseph Saint Luc, Lyon, France. ${ }^{8}$ Service de neurologie, Centre Hospitalier Saint Joseph Saint Luc, Lyon, France.

Received: 19 December 2020 Accepted: 5 May 2021

Published online: 13 May 2021

\section{References}

1. Zhu N, Zhang D, Wang W, Li X, Yang B, Song J, et al. A novel coronavirus from patients with Pneumonia in China, 2019. N Engl J Med. 2020:382:727-33.

2. Wu Z, McGoogan JM. Characteristics of and important lessons from the coronavirus disease 2019 (COVID-19) outbreak in China: summary of a report of 72314 cases from the Chinese Center for Disease Control and Prevention. JAMA. 2020;323:1239-42.

3. Grasselli G, Zangrillo A, Zanella A, Antonelli M, Cabrini L, Castelli A, et al. Baseline characteristics and outcomes of 1591 patients infected with SARS-CoV-2 admitted to ICUs of the Lombardy Region, Italy. JAMA. 2020;323(16):1574-81.

4. Taylor J, Rangaiah J, Narasimhan S, Clark J, Alexander Z, Manuel R, et al. Nosocomial COVID-19: experience from a large acute NHS Trust in SouthWest London. J Hosp Infect. 2020;106:621-5.

5. Korth J, Wilde B, Dolff S, Anastasiou OE, Krawczyk A, Jahn M, et al. SARSCoV-2-specific antibody detection in healthcare workers in Germany with direct contact to COVID-19 patients. J Clin Virol. 2020;128:104437. 
6. Lahner E, Dilaghi E, Prestigiacomo C, Alessio G, Marcellini L, Simmaco $M$, et al. Prevalence of Sars-Cov-2 infection in health workers (HWs) and diagnostic test performance: the experience of a teaching hospital in Central Italy. Int J Environ Res Public Health. 2020;17:4417.

7. Garcia-Basteiro AL, Moncunill G, Tortajada M, Vidal M, Guinovart C, Jiménez $A$, et al. Seroprevalence of antibodies against SARS-CoV-2 among health care workers in a large Spanish reference hospital. Nat Commun. 2020;11:3500

8. Treibel TA, Manisty C, Burton M, McKnight Á, Lambourne J, Augusto JB, et al. COVID-19: PCR screening of asymptomatic health-care workers at London hospital. Lancet. 2020;395(10237):1608-10.

9. Ong SWX, Tan YK, Chia PY, Lee TH, Ng OT, Wong MSY, et al. Air, surface environmental, and personal protective equipment contamination by severe acute respiratory syndrome coronavirus 2 (SARS-CoV-2) from a symptomatic patient. JAMA. 2020;323(16):1610-2.

10. Guan W-J, Ni Z-Y, Hu Y, Liang W-H, Ou C-Q, He J-X, et al. Clinical characteristics of coronavirus disease 2019 in China. N Engl I Med. 2020;382:1708-20.

11. Cheng H-Y, Jian S-W, Liu D-P, Ng T-C, Huang W-T, Lin H-H. Contact tracing assessment of COVID-19 transmission dynamics in Taiwan and risk at different exposure periods before and after symptom onset. JAMA Intern Med. 2020;180(9):1156-63.

12. He $X$, Lau EHY, Wu P, Deng $X$, Wang J, Hao $X$, et al. Temporal dynamics in viral shedding and transmissibility of COVID-19. Nat Med. 2020;26:672-5.

13. Roche Diagnostics Elecsys Anti-SARS-CoV-2 - IFU | FDA. https://www.fda. gov/media/144037/download. Accessed 14 July 2020.

14. Egger M, Bundschuh C, Wiesinger K, Gabriel C, Clodi M, Mueller T, et al. Comparison of the Elecsys ${ }^{\circledR}$ Anti-SARS-CoV-2 immunoassay with the $\mathrm{EDI}^{\mathrm{TM}}$ enzyme linked immunosorbent assays for the detection of SARSCoV-2 antibodies in human plasma. Clin Chim Acta. 2020;509:18-21.

15. Favresse J, Eucher C, Elsen M, Marie T-H, Dogné J-M, Douxfils J. Clinical performance of the Elecsys electrochemiluminescent immunoassay for the detection of SARS-CoV-2 total antibodies. Clin Chem. 2020;66(8):1104-6.

16. SPF. COVID-19: point épidémiologique du 9 juille2020. https://www. santepubliquefrance.fr/maladies-et-traumatismes/maladies-et-infectionsrespiratoires/infection-a-coronavirus/documents/bulletin-national/covid19-point-epidemiologique-du-9-juillet-2020. Accessed 15 July 2020.

17. Salje H, Tran Kiem C, Lefrancq N, Courtejoie N, Bosetti P, Paireau $J$, et al. Estimating the burden of SARS-CoV-2 in France. Science. 2020;369:208-11.

18. Fusco FM, Pisaturo M, lodice V, Bellopede R, Tambaro O, Parrella G, et al. COVID-19 among healthcare workers in a specialist infectious diseases setting in Naples, Southern Italy: results of a cross-sectional surveillance study. J Hosp Infect. 2020;105:596-600.

19. Steensels D, Oris E, Coninx L, Nuyens D, Delforge M-L, Vermeersch P, et al. Hospital-wide SARS-CoV-2 antibody screening in 3056 staff in a tertiary center in Belgium. JAMA. 2020;324(2):195-7.
20. Pérez-García F, Pérez-Zapata A, Arcos N, De la Mata M, Ortiz M, Simón E, et al. Severe acute respiratory coronavirus virus 2 (SARS-CoV-2) infection among hospital workers in a severely affected institution in Madrid, Spain: A surveillance cross-sectional study. Infect Control Hosp Epidemiol. 2020. https://doi.org/10.1017/ice.2020.1303.

21. Kim $\mathrm{H}, \mathrm{Hong} \mathrm{H}$, Yoon SH. Diagnostic performance of $\mathrm{CT}$ and reverse transcriptase-polymerase chain reaction for coronavirus disease 2019: a meta-analysis. Radiology. 2020;296:E145.

22. Shields A, Faustini SE, Perez-Toledo M, Jossi S, Aldera E, Allen JD, et al. SARS-CoV-2 seroprevalence and asymptomatic viral carriage in healthcare workers: a cross-sectional study. Thorax. 2020;75(12):1089-94.

23. Galán MI, Velasco M, Casas ML, Goyanes MJ, Rodríguez-Caravaca G, Losa-García JE, et al. Hospital-Wide SARS-CoV-2 seroprevalence in health care workers in a Spanish teaching hospital. Enferm Infecc Microbiol Clin. 2020. https://doi.org/10.1016/j.eimc.2020.11.015.

24. Li J, Fink JB, Ehrmann S. High-flow nasal cannula for COVID-19 patients: low risk of bio-aerosol dispersion. Eur Respir J. 2020;55:2000892.

25. Hua J, Qian C, Luo Z, Li Q, Wang F. Invasive mechanical ventilation in COVID-19 patient management: the experience with 469 patients in Wuhan. Crit Care. 2020;24:1-3.

26. Yang X, Yu Y, Xu J, Shu H, Xia J, Liu H, et al. Clinical course and outcomes of critically ill patients with SARS-CoV-2 pneumonia in Wuhan, China: a single-centered, retrospective, observational study. Lancet Respir Med. 2020;8:475-81.

27. Lescure F-X, Bouadma L, Nguyen D, Parisey M, Wicky P-H, Behillil S, et al. Clinical and virological data of the first cases of COVID-19 in Europe: a case series. Lancet Infect Dis. 2020;20:697-706.

28. Okba NMA, Müller MA, Li W, Wang C, GeurtsvanKessel CH, Corman $\mathrm{VM}$, et al. Severe acute respiratory syndrome coronavirus 2-specific antibody responses in coronavirus disease patients. Emerg Infect Dis. 2020;26:1478-88.

29. Seow J, Graham C, Merrick B, Acors S, Pickering S, Steel KJA, et al. Longitudinal observation and decline of neutralizing antibody responses in the three months following SARS-CoV-2 infection in humans. Nat Microbiol. 2020;5:1598-607.

30. Self WH, Tenforde MW, Stubblefield WB, Feldstein LR, Steingrub JS, Shapiro NI, et al. Decline in SARS-CoV-2 antibodies after mild infection among frontline health care personnel in a multistate hospital network - 12 States, April-August 2020. MMWR Morb Mortal Wkly Rep. 2020;69:1762-6.

\section{Publisher's Note}

Springer Nature remains neutral with regard to jurisdictional claims in published maps and institutional affiliations.

\section{Submit your manuscript to a SpringerOpen ${ }^{\circ}$ journal and benefit from:}

- Convenient online submission

- Rigorous peer review

- Open access: articles freely available online

- High visibility within the field

- Retaining the copyright to your article

Submit your next manuscript at $\boldsymbol{\nabla}$ springeropen.com 